\title{
ANALIZA UČESTALOSTI I STOPE OBOLIJEVANJA OD RAKA PROSTATE U FEDERACIJI BOSNE I HERCEGOVINE
}

\author{
Mate Đolo, Josip Šimić, Ivan Vasilj \\ Fakultet zdravstvenih studija, Sveučilište u Mostaru, 88000 Mostar, BiH \\ Rad je primljen 12.04.2019. Rad je recenziran 23.04.2019. Rad je prihvaćen 9.05.2019.
}

\section{SAŽETAK}

UVOD: Rak prostate najčešće je dijagnosticirani rak muške populacije u razvijenim zemljama i predstavlja drugi najčešći uzrok smrti od malignih bolesti u muškaraca. Zasad nisu poznati modificirajući čimbenici za nastanak raka prostate te zbog toga nije moguće djelovati preventivno na razvoj bolesti. Cilj ovog istraživanja bila je analiza učestalosti i stope obolijevanja od raka prostate u Federaciji Bosne i Hercegovine

ISPITANICI I POSTUPCI: Podatci o pobolu dobiveni su iz Zdravstveno statističkih godišnjaka FBiH te Registra raka Zavoda za javno zdravstvo FBiH. Podatci za R Hrvatsku dobiveni su iz periodičnih biltena Hrvatskog zdravstveno-statističkog ljetopisa i Registra za rak Hrvatskog zavoda za javno zdravstvo.

REZULTATI: U promatranom razdoblju registrirano je ukupno 1688 oboljelih osoba od raka prostate, s prosječnom incidencom 29,24/100 000. Omjer mortaliteta i registrirane incidence bio je 0,53. Najveća prosječna stopa obolijevanja bila je u Sarajevskoj (62,82/100 000) i Bosansko-podrinjskoj županiji (64,7/100 000). Najveći broj oboljelih (45,0 \%) bio je u životnoj dobi od 60 do 69 godina (p<0,001).U istom razdoblju u Hrvatskoj je registrirano ukupno 9494 oboljelih od raka prostate uz prosječnu stopu obolijevanja od 92,58/100 000.

ZAKLJUČAK: U promatranom petogodišnjem razdoblju primjetan je konstantni rast stope obolijevanja od raka prostate u Federaciji BiH. Izrazito mala stopa obolijevanja u odnosu na R Hrvatsku i zemlje u EU te mala razlika u omjeru između mortaliteta i incidencije bolesti, upućuje na znatnu subregistraciju oboljelih od raka prostate u F BiH.

Ključne riječi: javno zdravstvo, rak prostate, učestalost, Federacija Bosne i Hercegovine

Osoba za razmjenu informacija: dr. sc. Josip Šimić

E-mail: josip.simic@fzs.sum.ba

\section{UVOD}

Rak prostate najčešće je dijagnosticirani karcinom muške populacije u razvijenim zemljama, s incidencijom od 97 slučajeva na 100.000 muškaraca u zapadnoj Europi čime nadmašuje karcinom pluća i kolorektalni karcinom (1). Rak prostate pretežno pogađa starije muškarce, uz medijan dobi kod dijagnoze od 67 godina (2). Nadalje, predstavlja drugi najčešći uzrok smrti od malignih bolesti u muškaraca (3). Digitorektalni pregled (DRP), serumski prostata specifični antigen (PSA) i biopsija prostate pod kontrolom transrektalnog ultrazvuka (TRUZ) glavni su alati u dijagnostici (4). Zahvaljujući PSA probiru i dobroj informiranosti populacije u SAD-u se čak $91 \%$ karcinoma otkriva se u lokaliziranom stadiju (5). Zasad nisu poznati modificirajući čimbenici za nastanak karcinoma prostate te zbog toga nije moguće djelovati preventivno na razvoj bolesti. Ustanovljeni čimbenici rizika su dob, rasna 
pripadnost i obiteljska predispozicija (6). Za prognozu karcinoma prostate bitno je odrediti stupanj diferenciranosti samog tumora i stupanj progresije bolesti (7). Usprkos novim saznanjima o prirodi karcinoma prostate, učinkovitim dijagnostičkim metodama i novim minimalno invazivnim tehnikama liječenja, i dalje se malo zna o etiologiji. Dijagnostika karcinoma prostate danas je dostupnija i preciznija. Digitorektalni pregled (DRP), serumski prostata specifični antigen (PSA) i biopsija prostate pod kontrolom transrektalnog ultrazvuka (TRUZ) glavni su alati u dijagnostici (8). Danas postoje tri glavne opcije u terapiji klinički lokaliziranog karcinoma prostate: radikalna prostatektomija, radikalna radioterapija i pomno praćenje (watchfull waiting) $s$ uvođenjem terapije ako je to potrebno $(9,10)$. Trenutačne preporuke Američkog Udruženja urologa sugeriraju da u evaluaciji pacijenta s karcinomom prostate treba uzeti u obzir očekivano trajanje života i sveukupno zdravstveno stanje pacijenta te karakteristike karcinoma: Gleasonov zbroj i stupanj proširenosti bolesti (11). Liječenje metastatskog karcinoma prostate u domeni je rada onkologa (12).

Rak prostate veći je zdravstveni problem u razvijenijim zemljama koje imaju duži očekivani životni vijek (13). Po učestalosti rak prostate je na 6. mjestu svih uzroka smrtnosti od malignih bolesti i ujedno drugi najčešći zloćudni tumor kod muškaraca u Federaciji $\mathrm{BiH}$ (14). U 2015. godini u Federaciji $\mathrm{BiH}$ od raka prostate umrla su 234 muškaraca, što čini 9,35 \% svih smrti muškaraca od malignih neoplazmi (15). Za pretpostaviti je da se zbog starenja populacije, odnosno sve većeg broja muškaraca iznad pedesete godine života, ali i zbog bolje dijagnostike nego ranije može očekivati porast obolijevanja od ove bolesti.

\section{CILJ ISTRAŽIVANJA}

Cilj ovog istraživanja bio je odrediti učestalost raka prostate u Federaciji $\mathrm{BiH}$ u razdoblju od 2012. do 2016. godine te Utvrditi postoje li razlike u morbiditetu između pojedinih županija FBiH. Dodatni cilj istraživanja bio je usporediti dobivene podatke s epidemiološkim stanjem morbiditeta raka prostate $\mathrm{u}$ Republici Hrvatskoj u istom navedenom razdoblju.

\section{ISPITANICI I POSTUPCI}

Analizirani uzorak čine svi novoregistrirani slučajevi obolijevanja od raka prostate na području Federacije $\mathrm{BiH}$ u razdoblju 2012.-2016. godine.

Podatci o pobolu dobiveni su iz Zdravstveno statističkih godišnjaka FBiH te Registra raka Zavoda za javno zdravstvo FBiH. Podatci za R Hrvatsku dobiveni su iz periodičnih biltena Hrvatskog zdravstveno-statističkog ljetopisa i Registra za rak Hrvatskog zavoda za javno zdravstvo. U radu se koristila komparativna epidemiološka metoda.

Za utvrđivanje statističkih razlika između nominalnih i ordinarnih varijabli korišten je hi-kvadrat test. Kao razina značajnosti uzeta je vrijednost $p<0,05$, što znači da su rezultati kvantitativne analize podataka interpretirani na $5 \%$ razini značajnosti. Za statističku analizu korišten je programski sustav SPSS for Windows (inačica 13.0, SPSS Inc, Chicago, Illinois, SAD).

\section{REZULTATI}

U promatranom razdoblju registrirano je ukupno 1688 oboljelih osoba od raka prostate. U 2012. godini registrirano je 259 (15,2\%) osoba novooboljelih od raka prostate, 2013. godine registrirano je 319 $(18,7 \%)$ novooboljelih, 2014. godine registrirano je 350 (20,6 \%) novooboljelih, 2015. godine registrirano je $374(22,0 \%)$ novooboljelih te u 2016. godini $396(23,3 \%)$ novooboljelih $\left(\chi^{2}=33,549\right.$; d.f. 4 ; $\mathrm{p}<0,001)$.

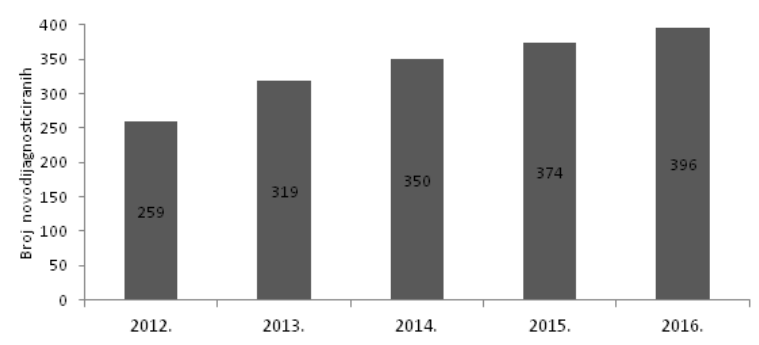

Slika 1. Broj novoregistriranih bolesnika s rakom prostate prema godinama u razdoblju 2012.-2016.

Prosječna incidenca raka prostate $\mathrm{u}$ navedenom razdoblju iznosila je 29,24/100 000. Analizirajući trend kretanja incidence raka prostateu razdoblju od 2012. do 2016. godine, bilježi se njen porast od 
$14,1 \%$. Prosječan mortalitet od raka prostate u navedenom razdoblju iznosio je 15,3/100 000. Omjer mortaliteta i registrirane incidence od raka prostate u F BiH u navedenom razdoblju bio je 0,53.

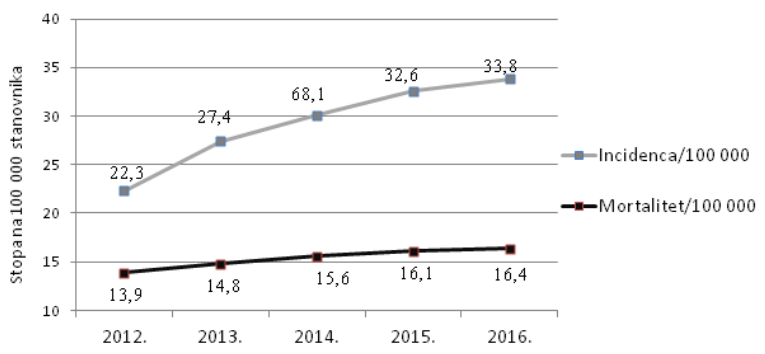

Slika 2. Prikaz kretanja i odnosa stope incidence i mortaliteta od raka prostate u $\mathrm{F} \mathrm{BiH}$ u razdoblju 2012.-2016.
U tablici 1 prikazan je broj novooboljelih od raka prostate i stopa obolijevanja u županijama $\mathrm{F}$ BiH u razdoblju 2012.-2016. Analizom prosječne stope obolijevanja bolesti u promatranom razdoblju pokazala se najveća prosječna stopa obolijevanja u Sarajevskoj i Bosansko-podrinjskoj županiji. Najniža prosječna stopa obolijevanja od raka prostate u promatranom razdoblju evidentirana je u Herceg-bosanskoj i Tuzlanskoj županiji (tablica 1 i slika 3)

Tablica 1. Novooboljeli i stopa obolijevanja od raka prostate - prikaz po županijama.

\begin{tabular}{llllllllllll}
\hline ŽUPANIJA & $\mathbf{2 0 1 2 .}$ & $\mathbf{2 0 1 3 .}$ & $\mathbf{2 0 1 4}$ & \multicolumn{2}{c}{$\mathbf{2 0 1 5 .}$} & \multicolumn{2}{c}{$\mathbf{2 0 1 6 .}$} \\
\cline { 2 - 11 } & $\mathrm{Br}$ & $\mathrm{Mb}$ & $\mathrm{Br}$ & $\mathrm{Mb}$. & $\mathrm{Br}$ & $\mathrm{Mb}$ & $\mathrm{Br}$. & $\mathrm{Mb}$. & $\mathrm{Br}$. & $\mathrm{Mb}$. \\
\hline Unsko-sanska & 47 & 32,2 & 22 & 15,1 & 21 & 14,4 & 22 & 14,7 & 24 & 15,1 \\
\hline Posavska & 5 & 24,1 & 6 & 28,5 & 6 & 28,7 & 9 & 30,1 & 11 & 31,1 \\
\hline Tuzlanska & 44 & 17,8 & 23 & 9,3 & 29 & 11,7 & 31 & 12,2 & 33 & 12,9 \\
\hline Zeničko dobojska & 49 & 25,1 & 44 & 22,5 & 43 & 22,0 & 45 & 22,4 & 47 & 22,9 \\
\hline Bosansko-podrinjska & 1 & 7,4 & 10 & 73,1 & 5 & 36,6 & 7 & 54,0 & 9 & 64,7 \\
\hline Srednjobosanska & 21 & 16,4 & 18 & 15,4 & 26 & 20,2 & 29 & 21,4 & 31 & 22,4 \\
\hline Hercegovačko-neretvanska & 20 & 18,3 & 29 & 28,7 & 33 & 30,2 & 35 & 30,7 & 38 & 31,3 \\
\hline Zapadno-hercegovačka & 8 & 19,7 & 10 & 24,6 & 10 & 24,6 & 11 & 25,1 & 12 & 25,6 \\
\hline Sarajevska & 55 & 24,3 & 134 & 59,8 & 171 & 76,1 & 179 & 76,7 & 184 & 77,3 \\
\hline Herceg-bosanska & 9 & 25,2 & 5 & 13,7 & 6 & 16,5 & 6 & 16,5 & 7 & 17,5 \\
\hline
\end{tabular}

${ }^{*} \mathrm{Br}$ - broj novoregistriranih od raka prostate

${ }^{*} \mathrm{Mb}$ - stopa obolijevanja od raka prostate na 100000 stanovnika

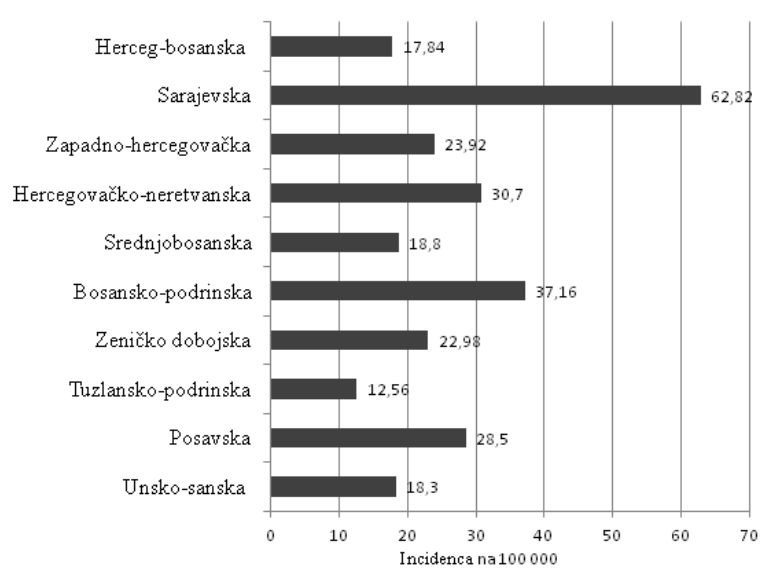

Slika 3. Prosječna stopa obolijevanja od raka prostate u županijama.
Najveći broj oboljelih 760 (45,0 \%) bio je u životnoj dobi od 60 do 69 godina ( $\chi^{2}$ test $=1020,944$; d.f. 4 ; $\mathrm{p}<0,001)$.

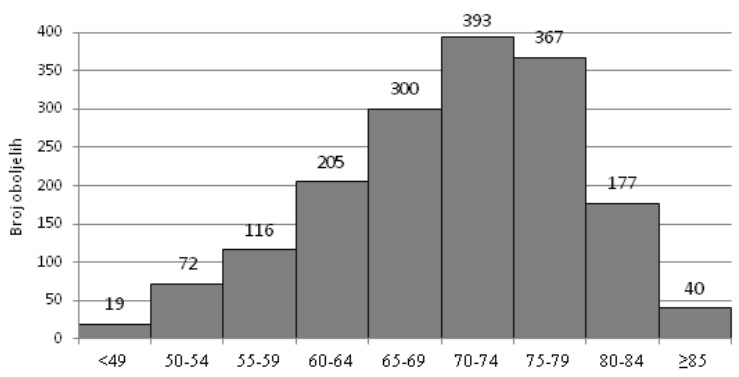

Slika 4. Životna dob oboljelih od raka prostate u F $\mathrm{BiH}$ u razdoblju 2012.-2016. 
Slika 5 prikazuje stopu obolijevanja od raka prostate u Hrvatskoj u razdoblju 2012.-2016. godine. U razdoblju od 2012. do 2016. godine registrirano je ukupno 9494 oboljelih od raka prostate uz prosječnu stopu obolijevanja od 92,58/100 000. U 2012. godini registrirano je 1758 osoba oboljelih od raka prostate, 2013. godine registrirano je 1698 oboljelih, 2014. godine 1708 oboljelih, u 2015. godini 2141 te u 2016. godini 2189 novooboljelih od raka prostate. Prosječan mortalitet od raka prostate u navedenom razdoblju iznosio je 38,91100 000. Prosječan omjer mortaliteta i registrirane incidence od raka prostate bio je 0,42 .

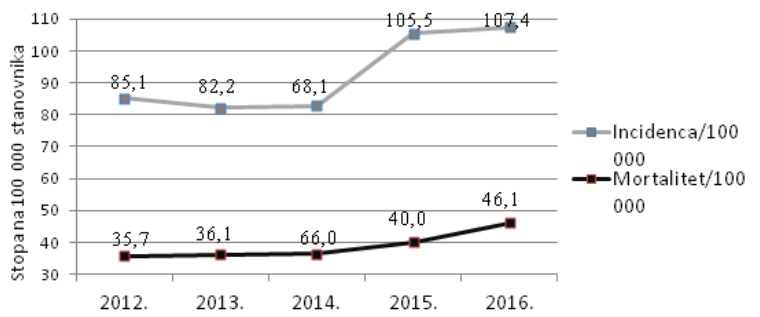

Slika 5. Prikaz odnosa incidence i mortaliteta od raka prostate u R Hrvatskoj u razdoblju 2012.-2016.

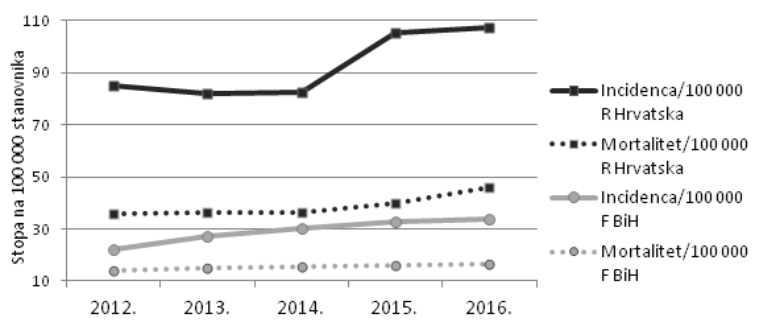

Slika 6. Prikaz odnosa incidence i mortaliteta od raka prostate između F BiH i R Hrvatske.

\section{RASPRAVA}

Rak, drugi po učestalosti uzrok smrti, odmah iza bolesti srca i krvnih žila, a zbog visoke učestalosti faktora rizika za njegov nastanak, kao i produženog očekivanog trajanja života stanovnika, time i daljnjeg porasta broja novooboljelih od raka, predstavlja značajan javnozdravstveni problem. Karcinom prostate postaje skoro najčešća maligna bolest muškaraca. U Europi je najčešći solidni maligni tumor muškaraca sa incidencom 214 na 1000 muškaraca. Nadalje, predstavlja drugi najčešći uzrok smrti od malignih bolesti u muškaraca (16).
U ovom radu su korišteni podatci o osobama kojima je dijagnoza raka prostate postavljena u razdoblju od 2012. do 2016. godine, a čije su prijave dostavljene u Registar raka FBiH. U promatranom petogodišnjem razdoblju registrirano je ukupno 1688 oboljelih muškaraca od raka prostate u F $\mathrm{BiH}$, uz prosječnu stopu obolijevanja od 29,4/100 000 stanovnika. Prosječna je stopa obolijevanja od raka prostate u Hrvatskoj u istom razdoblju iznosila $92,58 / 100000$, što je više od tri puta više od stope obolijevanja u F BiH.

Analizom prosječne stope obolijevanja u promatranom razdoblju pokazala se najveća prosječna stopa obolijeva u Sarajevskoj i Bosansko-podrinjskoj županiji. Najniža prosječna stopa obolijevanja od raka prostate u promatranom razdoblju evidentirana je u Herceg-bosanskoj i Tuzlansko-podrinjskoj županiji. Zemljopisne varijacije u incidenciji i stopama smrtnosti od raka prostate uglavnomsu bile tumačene u prilog okolišnim i, posebice, prehrambenim uzročnim mehanizmima. Činjenica da se rizik modificira migracijama ukazuje da se te varijacijemogu prije pripisati egzogenim čimbenicima nego genetskoj predispoziciji. Na primjer, osobe koje su u Sjedinjene Države imigrirale iz Japana imaju veću smrtnost od raka prostate nego osobe slične dobi koje su ostale u Japanu (17).

Tri četvrtine oboljelih u ovom istraživanju su u dobi 65 i više godina. Stope incidencije raka prostate rastu s dobi, a posebice nakon 60-70 godine života. Rak prostate je rijetkost u mlađih muškaraca, a rizik raste s dobi. Rizik za taj rak u SAD-u ima svaki šesti muškaraca tijekom života. Šansa obolijevanja raste naglo nakon 50. godine života. Oko dvije trećine svih slučajeva raka prostate dijagnosticira se u muškaraca u dobi iznad 65 godina (18).

Rezultati ovog istraživanja ukazuju na neujednačenost trenda i nedostatan obuhvat i kvalitetu prijavljivanja malignih bolesti u F BiH. U F BiH se prosječno se registrira blizu 5000 novih slučajeva raka godišnje, s prosječnom stopom pojavnosti 191,5/100000 što je mnogo manje nego u zemljama u okruženju (Hrvatska, 535,3/100 000; Slovenija $475,3 / 100$ 000) ili prosjek u zemljama EU $(369,4 / 100$ 000) $(18,19)$. 
U promatranom razdoblju, omjer mortaliteta i incidencije $(0,53)$ od raka prostate ukazuje na znatnu subregistraciju oboljelih. Razlog su nedostatan kvalitet i nepravovremeno prikupljanje budući da je teža dostupnost podataka (deset županija u FBiH, te u svakom od njih sve zdravstvene ustanove na primarnom, sekundarnom i tercijarnom nivou). Dakle za razliku od drugih država u okruženju $\mathrm{F}$ BiH je decentralizirano prikupljanje podataka što u velikoj mjeri usložnjava proces epidemiološke statistike.

Rezultati istraživanja su pokazali trenda rasta učestalosti obolijevanja od raka prostate u Federaciji $\mathrm{BiH}$ u promatranom petogodišnjem razdoblju. Tako da je od incidencije 22,3/100 000 koliko je zabilježeno u 2012., kroz petogodišnje razdoblje laganog opadanja stope obolijevanja, u 2016. godini zabilježena stopa obolijevanja od 33,8/100 000 stanovnika, što je iznosilo porast od $14,1 \%$. I u drugim zemljama je opažen porast incidencije od raka prostate i to ne samo u zemljama s visokim rizikom za taj rak nego i u zemljama s nižim rizikom. Nasuprot tome, izgleda da noviji porast incidencije nije povezan s promjenama uzročnih čimbenika.Većina dokaza ukazuje da se ove promjene velikim dijelom mogu pripisati promjenama u otkrivanju raka prostate (20).

Dosadašnja iskustva na uspostavi i vođenju populacijskog registra raka pokazuju njegovu ulogu u procjeni epidemiološkog profi la raka u $\mathrm{FBiH}$, opterećenosti društva rakom (incidencija, mortalitet), analizu vremenskih trendova (dob, spol, mjesto), ali i potrebu poboljšanja kvalitete registracije i korekcija uočenih nedostataka. Obzirom na velike oscilacije trenda, velikog udjela registriranih samo na osnovu potvrde o smrti i kašnjenja u prijavljivanju, podatci u Populacijskom registru raka su još uvijek nestabilni i ne odražavaju pravu sliku pojavnosti raka u Federaciji BiH. S obziromna sadašnje nedostatno poznavanje čimbenika rizika, perspektive za primarnu prevenciju su slabe. U sekundarnoj prevenciji kao metoda probira preporuča se godišnji digitorektalni pregled, utvrđivanje prostata specifičnog antigena kod muškaraca starijih od 50 godina.

\section{ZAKLJUČAK}

U promatranom petogodišnjem razdoblju od 2012. do 2016. godine primjetan je konstantni rast stope obolijevanja od raka prostate u Federaciji BiH. Pokazala se značajna razlika u stopi obolijevanja među županijama. Najveća prosječna stopa obolijevanja zabilježena je u Sarajevskoj i Bosansko-podrinjskoj županiji, dok je najniža prosječna stopa obolijevanja evidentirana u Herceg-bosanskoj i Tuzlansko-podrinjskoj županiji. Rak prostate se u statistički značajnoj većini najučestalije pojavljuje u muškaraca u životnoj dobi od 79 do 79 godina. Federacija $\mathrm{BiH}$ ima 3,1 puta manju stopu obolijevanja od raka prostate $\mathrm{u}$ odnosu na R. Hrvatsku. Izrazito mala stopa obolijevanja u odnosu na R. Hrvatsku i zemlje u EU te mala razlika u omjeru između mortaliteta i incidencije bolesti, upućuje na znatnu subregistraciju oboljelih od raka prostate u $\mathrm{F} \mathrm{BiH}$. 


\section{LITERATURA}

1. Ferlay J, Soerjomataram I, Dikshit R, Eser S, Mathers C, Rebelo M, i sur. Cancer incidence and mortality worldwide: sources, methods and major patterns in globocan 2012. Int J Cancer 2015;136:359-86.

2. Jemal A, Siegel R, Ward E, i sur. Cancer statistics, 2008. CA Cancer J Clin 2008;58:71-96.

3. GLOBOCAN 2008 Fast stats: Estimated age-standardised incidence and mortality rates. Geneva: WHO 2008.

4. Jermal A, Siegel R, Ward E, Murray T, Xu J, Smigal C i sur. (2006) Cancer statistics. CA Cancer J Clin 2011;56:106.

5. Albano JD, Ward E, Jemal A i sur. Cancer mortality in the United States by education level and race. J Natl Cancer Inst 2009;99:1384-94.

6. Ilic D, O'Connor D, Green S, Wilt T. Screening for prostate cancer: a Cochrane systematic review. Cancer Causes Control 2011;18:279-85.

7. Budäus L, Huland H, Graefen M. Controversies in the management of localized prostate cancer: Radical prostatectomy still the standard of care. Crit Rev Oncol Hematol 2012;84:24-9.

8. Candas B, CusanL, Gomez JL i sur. Evaluation of prostate specific antigen and digital rectal examination as screening tests por prostate cancer. Prostate 2000;45:19-35.

9. Bill-Axelson A, Holmberg L, Ruutu M, et al. Radical prostatectomy versus watchful waiting in early prostate cancer. N Engl J Med 2011;364:1708-17.

10. Petrylak DP. Chemotherapy for advanced hormone refractory prostate cancer. Urology 1996;54:30-5.

11. Tanagho EA, McAninch JW. Smith's General Urology, (17e). New York: Lange Medical Books/The McGraw-Hill Companies; 2014.
12. Pasini J. Prostatic carcinoma. Medicus; 2010;10:201-5

13. Center MM, Jemal A, Lortet-Tieulent J, i sur.International variation in prostate cancer incidence and mortality rates. Eur Urol 2012;61:107992.

14. Pregled malignih neoplazmi - Registar raka FBiH. [Internet] dostupno na: http://www. zzjzfbih.ba/wp-content/uploads/2013/02/Pregled-malignih-neoplazmi.pdf (pristupljeno 26.01.2018.)

15. Zdravstveno stanje stanovništva i zdravstvena zaštita u Federaciji Bosne i Hercegovine 2015. Zavod za javno zdravstvo FBiH. Sarajevo; 2016. godine

16. Boyle P, Ferlay J. Cancer incidence and mortality in Europe 2014. Ann Oncol 2015;16:481-8.

17. World Cancer Reasearch Fund/American Institute for Cancer Research. Food, Nutrition and the Prevention of Cancer: a Global Perspective. Washington DC: American Institute for Cancer Research 1997:310-23.

18. Hemminki K, Rawal R, Bermejo JL. Prostate cancer screening changing age specific incidence trends and implications on familial risk. Int J Cancer 2005; 113:315-5.

19. Hsing AW, Tsao L, Devesa SS. International trends and patterns of cancer incidence and mortality. Int J Cancer 2000; 85:60-7.

20. Baade PD, Coory MD, Aitken JF. International trends in prostate-cancer mortality: the decrease is continuing and spreading. Cancer Causes Control 2014;15:237-41. 


\title{
ANALYSIS OF PROSTATE CANCER INCIDENCE IN THE FEDERATION OF BOSNIA AND HERZEGOVINA
}

\author{
Mate Đolo, Josip Šimić, Ivan Vasilj \\ Faculty of Health Studies, University of Mostar, 88000 Mostar, Bosna i Hercegovina
}

\begin{abstract}
INTRODUCTION: Prostate cancer is the most commonly diagnosed cancer among the male population in developed countries and it is the second leading cause of cancer deaths among men. Modifying factors for the development of prostate cancer are still unknown and therefore it is not possible prevent the development of the disease. The objective of this study was to analyse the incidence of prostate cancer in the Federation of Bosnia and Herzegovina.

SUBJECTS AND METHODS: Morbidity data were obtained from the Annual Health Statistics of the Federation of Bosnia and Herzegovina and the Cancer Registry of the Institute for Public Health of FB\&H. Data from the Republic of Croatia were obtained from the Croatian Health Statistics Yearbook and the Croatian National Cancer Registry.

RESULTS: In the observation period, a total of 1,688 people affected by prostate cancerwere registered with an average incidence rate of $29.24 / 100,000$. The ratio of mortality and registered incidence was 0.53 . The highest morbidity rate was in the Sarajevo Canton $(62.82 / 100,000)$ and The Bosnian-Podrinje Canton $(64.7 / 100,000)$. The largest number of patients was between the ages of 60 and $69(\mathrm{p}<0.001)$. In the same period, there was a total of 9,449 prostate cancer patients registered in Croatia with an average morbidity rate of $92.58 / 100,000$.

CONCLUSION: During the observation period of five years, there was a constant growth of the morbidity rate for prostate cancer in the Federation of Bosnia and Herzegovina. There was an extremely low morbidity rate when compared to Croatia and other countries of the EU as well as a slight difference in the ratio of mortality and incidence of the disease which suggests to a low registration rate of prostate cancer patients in FB\&H.
\end{abstract}

Key words: cancer, prostate, morbidity, diagnostics, treatment

Correspondence: Josip Šimić

Email: josip.simic@fzs.sum.ba 